\title{
Evaluation of Cardiovascular Risk of Selective and Nonselective Cyclooxygenase Inhibitors (COX-Is) in Arthritic Patients: A Comparative Matched Case Control Study
}

\author{
N. Quraishi, U. Bhosale ${ }^{*}$ R. Yegnanarayan, and D. Devasthale ${ }^{1}$ \\ Department of Pharmacology and Orthopedics SKNMC, Narhe (Ambegaon) Pune-41, Maharashtra \\ India
}

Received 16 November 2013, accepted in final revised form 26 January 2014

\begin{abstract}
This study was conducted to assess and compare the cardiovascular risk and to explore the demography of $\mathrm{CV}$ risk of nonselective cyclooxygenase inhibitors (COX-Is) and selective COX-2-Is in arthritic patients. In this comparative matched case control study adult arthritic patients of either sex taking COX-Is for $\geq 1 \mathrm{yr}$; were included. Arthritic age and sex matched individuals with no history of COX-Is treatment were the controls. Patients with history of any other disease (e.g. diabetes, hypertension, stroke, IHD etc.) were excluded. Patients were grouped into Control, nonselective COX-I and selective COX-2-I groups. The CV risk factors like blood pressure, blood sugar level (BSL), lipid profile, BMI (body mass index) etc. were assessed and compared; demography of CV risk factors i.e. age, sex, smoking, alcohol, heredity was also studied. Qualitative data were analyzed using Chi-square and quantitative data were analyzed by student's ' $t$ ' - test. Study clearly revealed that all NSAIDs exhibit significant $\mathrm{CV}$ risk when taken over a period of time as in arthritis. However selective COX 2-Is found to exhibit more CV risk in this regard. Odds ratio (OR) for CV risk $=10.3(95 \% \mathrm{CI}: 1.45,3.31)$ and $\mathrm{OR}$ for $\mathrm{CV}$ risk $=5.2(95 \% \mathrm{CI}: 1.05,2.57)$ for nonselective COX-Is. BMI, BSL and lipid profile; the potential CV risk factors, showed significant impairment in selective COX 2-Is group; $P<0.05, P<0.05$ and $P<0.01$ (HDL), $\mathrm{P}<0.001$ (cholesterol), respectively compared to controls and $P<0.05$ compared to nonselective COX-Is. This study portrays the potential CV risk of selective COX 2-Is and confirms and re-evaluate the results of earlier studies in this regard.
\end{abstract}

Keywords: Anti-arthritic agents; BMI; COX-Is; CV risk; Lipid profile.

(c) 2014 JSR Publications. ISSN: 2070-0237 (Print); 2070-0245 (Online). All rights reserved. doi: http://dx.doi.org/10.3329/jsr.v6i2.17039 J. Sci. Res. 6 (2), 329-338 (2014)

\section{Introduction}

Arthritis is the most prevalent disease involving middle age and elderly (50-65yrs) and go on increasing in prevalence with age above 65yrs [1]. Millions of elderly people take nonsteroidal anti-inflammatory drugs (NSAIDs), selective and nonselective, because of their analgesic and anti-inflammatory benefits [2]. However, many questions remain about

\footnotetext{
*Corresponding author: umabhosale2000@gmail.com
} 
the cardiovascular (CV) safety of selective cyclooxygenase 2 inhibitors (COX-Is) as well as nonselective NSAIDs, particularly in older adults [3]. During the past 2 years, a great deal of evaluation has been conducted on the CV effects of NSAIDs. Clinical trial databases for these COX-Is have shown variable effects on CV risk factors. There is lots of controversy regarding cardiovascular safety of the selective and nonselective COXinhibitors.

Results of the Vioxx Gastrointestinal Outcomes Research (VIGOR) trial have suggested an increased risk of CV events in patients taking COX2-Is [4]. Adenomatous Polyp Prevention on Vioxx (APPROVe) resulted in withdrawal of rofecoxib from all markets voluntarily; Adenoma Prevention with Celecoxib (APC) have showed higher cardiovascular risk of celecoxib, at the same time the second study; Prevention of Adenomatous Polyps (PreSAP) [5], did not verify these results. Surprisingly, the third study Alzheimer Disease and Prevention Trial (ADAPT) proved 50\% increase of the risk of CV events of naproxen instead of celecoxib [6].Therapeutic Arthritis Research and Gastrointestinal Event Trial (TARGET) have showed a three to four-fold reduction in ulcer complications in lumiracoxib treated patients compared with non-steroidal antiinflammatory drugs without an increase in the rate of serious cardiovascular events [7]. Coronary artery bypass graft (CABG No.1 and No.2), several case-control, cohort studies and pooled meta-analysis studies have also showed conflicting results [8].

On the basis of these findings, rofecoxib, valdecoxib and lumiracoxib have been withdrawn from the market worldwide; explanation for the increased CV risk however still remained elusive [9-11]. Celecoxib, etoricoxib and parecoxib still available for use and lumiracoxib being considered for Food and Drug Administration (FDA) approval and cimicoxib in preclinical testing [12]. A recent meta-analysis study of randomized controlled trials have showed no significant differences in cardiovascular outcomes between lumiracoxib and placebo or between lumiracoxib and other NSAIDs in patients with osteoarthritis [13], however, it's not available in India and banned in several countries in 2007-08. The question of whether COX2-Is having a greater risk than nonselective NSAIDs must be answered.

This study is therefore focused on the effects of the nonselective and selective COX2Is on CV risk factors like blood pressure, blood sugar level (BSL), lipid profile, BMI (Body mass index) etc. Efforts were also taken to study the demographics of CV risk factors (i.e. age, sex, smoking, alcohol, heredity). This study re-evaluates and confirms the results of earlier studies in this regard.

\section{Materials and Methods}

In this comparative matched case control study adult arthritic patients of either sex taking COX-Is treatment for $\geq 1 \mathrm{yr}$; were included. Arthritic age and sex matched individuals 
with no history of COX-Is treatment were the controls. Patients those with history of any other disease (e.g. diabetes, hypertension, stroke, IHD etc.) and medical treatment for the same were excluded. Initial ECG screening of every patient was done to rule out the cardiovascular disease. Patients were divided into Control, nonselective COX-I and selective COX 2-I groups $(n=30)$ after getting the protocol approved by institutional ethics committee (Ref: SKNMC NO/Ethics/Corr/2011/103). Their CV risk factors i.e. blood pressure, BSL, lipid profile, BMI etc. were assessed and compared and demographics of $\mathrm{CV}$ risk factors (i.e. age, sex, smoking, alcohol, heredity) were also studied. BMI calculated by online BMI calculator while, 10 year CV risk was calculated using online Framingham's calculator. Statistical tests used was Chi-square for qualitative data analysis and quantitative data was analyzed by student's 't'-test using Vassar-stats statistical software package.

\section{Results}

In this matched case control study we have assessed the effects of NSAIDs on CV risk factors in arthritic patients over a period of time ( $\geq 1 \mathrm{yr})$. The demographic profiles of these arthritic patients were also studied and are presented in Table 1 . There were 10 males and 20 females enrolled in each group with mean age 50.7yrs. Subset arthritic patients with history of smoking were 13, alcohol consumption 8 and familial CVD 28. Arthritic patients with family history of CVD were maximum (15 out of 28) in selective COX 2-Is group. Arthritics in nonselective and selective COX 2-Is group received eight different NSAIDs (see Fig. 1). Among nonselective NSAIDs, diclofenac sodium was received by majority of the patients $(23 \%)$ followed by aceclofenac (10\%) and only $2 \%$ were treated by indomethacin. In selective COX 2-Is $47 \%$ arthritics received etoricoxib and $3 \%$ received celecoxib.

Table 1. Demographic profile of the arthritic patients.

\begin{tabular}{lccc}
\hline $\begin{array}{l}\text { Characteristics } \\
(N=30)\end{array}$ & Control & Nonselective COX-Is & Selective COX2-Is \\
\hline Age $($ mean \pm SD $)$ & $50.7 \pm 12.6$ & $50.6 \pm 9.8$ & $50.7 \pm 12.7$ \\
Sex & & & \\
$\cdot$ Male & 10 & 10 & 10 \\
$\bullet$ Female & 20 & 20 & 20 \\
Smokers & 3 & 5 & 5 \\
Alcoholic & 2 & 2 & 4 \\
Family history of CVD & 6 & 7 & 15 \\
\hline
\end{tabular}




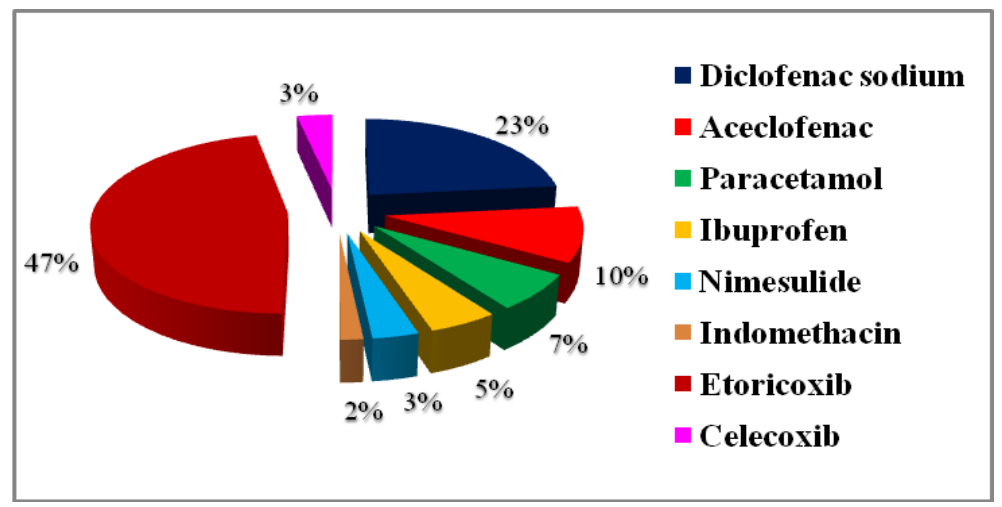

Fig. 1. Distribution of Cyclooxygenase inhibitors use in arthritic patients $(N=60)$.

Results of this study clearly revealed that all NSAIDs reason potential CV risk when taken over a period of time as in arthritic patients. However selective COX 2-Is found to impart higher $\mathrm{CV}$ risk in this regard. BMI, BSL and lipid profile; the potential CV risk factors, showed statistically significant impairment in selective COX 2-Is treated group arthritic patients; $P<0.05, P<0.05$ and $P<0.01$ (HDL), $P<0.001$ (cholesterol) respectively compared to controls and $P<0.05$ compared to nonselective COX-Is group. Triglycerides (TGs) were apparently increased in COX 2-Is group but this increase was statistically insignificant. No significant effect was observed on systolic and diastolic blood pressure (see Table 2, Fig. 2).

Table 2. Effect of cyclooxygenase-2 selective and nonselective NSAIDs on cardiovascular risk factors.

\begin{tabular}{lccccccc}
\hline $\begin{array}{l}\text { Treatment } \\
\text { groups }\end{array}$ & BMI & SBP & DBP & $\begin{array}{c}\text { Random } \\
\text { BSL }\end{array}$ & HDL & TGs & Cholesterol \\
\hline Control & $23.8 \pm 3$ & $123.4 \pm 10.4$ & $80 \pm 7.6$ & $109.7 \pm 12.2$ & $51.7 \pm 20.2$ & $121.8 \pm 65.5$ & $173.6 \pm 25$ \\
$\begin{array}{l}\text { Nonselective } \\
\text { COX-Is }\end{array}$ & $23.8 \pm 5.1$ & $124.4 \pm 14.3$ & $81 \pm 9.2$ & $113 \pm 38.9$ & $42.9 \pm 11.3^{*}$ & $129.3 \pm 45.7$ & $180.6 \pm 43.7$ \\
$\begin{array}{l}\text { Selective } \\
\text { COX 2-Is }\end{array}$ & $26.5 \pm 4.8^{* \dagger}$ & $125.2 \pm 10.6$ & $81.4 \pm 6.9$ & $118.2 \pm 14.6^{*}$ & $36.7 \pm 17.8^{* *+}$ & $147.9 \pm 46.9$ & $203.6 \pm 35.5^{* * *+}$ \\
\hline
\end{tabular}

$N=30$, values are Mean \pm SD. ${ }^{*} P<0.05,{ }^{* *} P<0.01,{ }^{* * *} P<0.001$ compared to control and ${ }^{\dagger} P<0.05$ compared to Nonselective COX-I group. SBP: Systolic blood pressure, DBP: Diastolic blood pressure, HDL: High density lipoprotein, TGs: Triglycerides. 


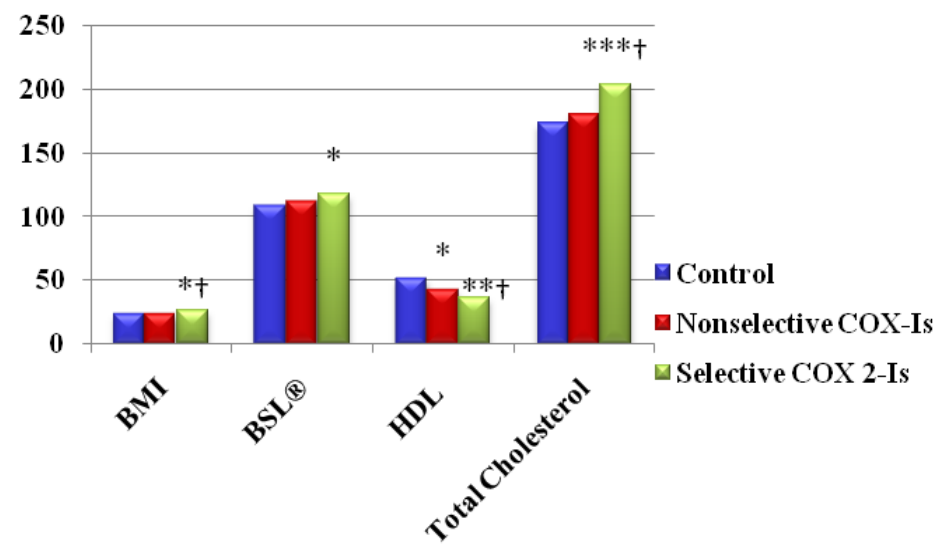

Fig. 2. Cardiovascular risk of cyclooxygenase- 2 selective and nonselective NSAIDs. $\mathrm{N}=30$; $* P<0.05, * * P<0.01, * * * P<0.001$ compared to control and $\uparrow P<0.05$ compared to nonselective COXI group.

From the result it also becomes evident that patients in selective COX 2-Is group were 10.3 times more likely to have $\mathrm{CV}$ risk and patients taking non-selective NSAID were 5.2 times more likely to have $\mathrm{CV}$ risk as compared to patients not taking any medicine for arthritis. It can also be said that selective COX 2-Is more harmful with OR for CV risk $=10.3$ (95\% CI: $1.45,3.31)$ and have more $\mathrm{CV}$ risk as compared to nonselective COX Is with OR for CV risk= 5.2 (95\%CI: 1.05, 2.57) (see Table 3).

Table 3. Cardiovascular risk of cyclooxygenase-2 selective and nonselective NSAIDs

\begin{tabular}{lccc}
\hline \multicolumn{1}{c}{ Outcome } & $\begin{array}{c}\text { Controls } \\
\text { without drug intake }\end{array}$ & $\begin{array}{c}\text { Cases with } \\
\text { selective COX 2-Is }\end{array}$ & $\begin{array}{c}\text { Cases with } \\
\text { nonselective COX-Is }\end{array}$ \\
\hline With CV risk & 3 & 16 & 11 \\
Without CV risk & 27 & 14 & 19 \\
Total & 30 & 30 & 30 \\
OR (95\% CI) & $10.3(1.45,3.31)$ & $5.2(1.05,2.57)$ \\
RR & 2.47 & 1.09 \\
\hline
\end{tabular}

$N=30$, test used is chi-square. OR: Odds ratio, RR: relative risk and CI: $95 \%$ confidence interval.

When 10 year CV risk was assessed using Framingham's calculator; maximum over all CV risk percentage was reflected in selective COX 2-Is treated arthritics (see Table 4). While significantly higher risk of getting CHD and MI $(P<0.05)$ and apparently high risk 


\section{Evaluation of Cardiovascular Risk}

of stroke, CVD, CHD death and CVD death ( $p>0.05)$ over 10 years was also observed in arthritic patients treated with selective COX 2-Is and same was observed in subset arthritic patients (see Tables 5 and 6).

Table 4. Comparative 10 year CV risk in cyclooxygenase-2 selective and nonselective NSAIDs treated arthritic patients.

\begin{tabular}{lccc}
\hline$\%$ 10 year CV Risk & Control & Nonselective COX-Is & Selective COX 2-Is \\
\hline$<1 \%$ & 10 & 08 & 08 \\
$1-5 \%$ & 13 & 15 & 12 \\
$5-15 \%$ & 07 & 05 & 05 \\
$15-30 \%$ & 00 & 02 & 03 \\
$>30 \%$ & 00 & 00 & 02 \\
Total & 30 & 30 & 30 \\
\hline
\end{tabular}

$N=30$, values are number of patients with variable percentage $\mathrm{CV}$ risk.

Table 5. Comparative 10 year risk of CHD, MI, stroke, CVD, CHD death and CVD death in arthritic patients.

\begin{tabular}{lcccccc}
\hline Drug groups & CHD & MI & Stroke & CVD & \multicolumn{2}{c}{ CHD death CVD death } \\
\hline Control & $5.3 \pm 1.9$ & $2.1 \pm 1.1$ & $1.3 \pm 0.9$ & $8.2 \pm 3.2$ & $0.8 \pm 0.5$ & $1.5 \pm 1.1$ \\
$\begin{array}{l}\text { Nonselective } \\
\text { COX-Is }\end{array}$ & $7.1 \pm 2.8$ & $3.5 \pm 2$ & $1.4 \pm 0.6$ & $10.1 \pm 4.1$ & $1.4 \pm 1$ & $1.7 \pm 1.1$ \\
$\begin{array}{l}\text { Selective COX } \\
\text { 2-Is }\end{array}$ & $12 \pm 5.6^{*}$ & $6.5 \pm 4.1^{*}$ & $1.9 \pm 1.1$ & $14.8 \pm 6.9$ & $3.6 \pm 3$ & $4.6 \pm 3.9$ \\
\hline
\end{tabular}

$N=30$, values are mean \pm SD. $* P<0.05$ compared to control. CHD: Coronary heart disease, MI: Myocardial infarction, CVD: Cardiovascular disease.

Table 6. Comparative 10 year CV risk in subset arthritic patients.

\begin{tabular}{lccc}
\hline Drug groups & $\begin{array}{c}\text { Smokers } \\
(\mathrm{n})\end{array}$ & $\begin{array}{c}\text { Alcoholic } \\
(\mathrm{n})\end{array}$ & $\begin{array}{c}\text { Family history of CVD } \\
(\mathrm{n})\end{array}$ \\
\hline Control & $8.6 \%(3)$ & $7.5 \%(2)$ & $2.3 \%(6)$ \\
Nonselective COX-Is & $9.3 \%(5)$ & $10 \%(2)$ & $2.5 \%(7)$ \\
Selective COX 2-Is & $23 \%(5)$ & $20 \%(4)$ & $9.6 \%(15)$ \\
\hline
\end{tabular}




\section{Discussion}

Arthritis is the most prevalent disease involving middle age and elderly i.e. 50-65yrs and go on increasing in prevalence with age i.e. $>65 y$ rs, the incident rate of arthritis is 3 times higher in females compared to males [1] . In this study also Male/Female ratio was found to be 1:2 (i.e. 30 men and 60 women) with mean age $50.7 \mathrm{yrs}$, suggestive of high incidence rate in middle age women.

In present study eight different NSAIDs were received by arthritic patients; among nonselective COX-Is group 66\% patients received diclofenac sodium and aceclofenac (i.e. phenylacetic acid derivatives) remaining patients were treated with other nonselective NSAIDs. In selective COX 2-Is group 94\% patients received etoricoxib while only 6\% treated with celecoxib. Results of this study revealed that COX 2-Is cause significant increase in BMI, BSL and also significant impairment in lipid profile of arthritic patients. Nonselective COX-Is also showed impairment in lipid profile of the arthritics but except HDL this impairment was statistically insignificant. The effect of selective COX 2-Is on these CV risk factors could be attributed to etoricoxib as $94 \%$ of patients received etoricoxib while in nonselective COX-Is, this effects should be attributed to phenylacetic acid derivative with similar properties.

Presently rofecoxib, valdecoxib and lumiracoxib have been withdrawn from the market worldwide on the basis of results of various trials viz. VIGOR, APPROVe and TARGET [4, 5, 7]. Conflicting results of several clinical trials about CV safety of celecoxib created controversies [5, 6, 14]. Comparatively cardiovascular safety data about etoricoxib is scare although few clinical trials stated that etoricoxib exhibit less or comparable CV risk to nonselective NSAIDs and did not appear to significantly increase the risk for MI and stroke [15-17]. But in our study it has reasoned significant risk for CHD and MI $(P<0.05)$ whereas reflected apparent increase in risk of stroke, CVD and death due to CHD and CVD which was statistically insignificant compared to controls as well as nonselective COX-Is. In nonselective NSAIDs (i.e. diclofenac sodium and aceclofenac as mentioned above) also there was apparent increase in risk of CHD, MI and CVD compared to controls $(P>0.05)$. Hence though the results of our study confirm that selective COX 2-Is exhibit comparable CV risk to nonselective NSAIDs; our study results are in disagreement with the earlier studies that states selective COX 2-Is exhibit less CV risk and did not significantly increase the risk for MI and stroke.

Increased CV risk of selective COX 2-Is is said to be due inhibition of formation of the vasodilator PGI2, and leaving TXA2 unopposed, which facilitates vasoconstriction, platelet activation, and smooth muscle cell proliferation but, their exact role on lipid profile, atherosclerosis and plaque formation is still unclear [18]. Recently molecular studies have identified cytochrome p-450(CYP) pathway in arachidonic acid (AA) metabolism along with COX and lipooxygenase pathway (LOX). CYP epoxygenases are known to metabolize AA to four regioisomeric epoxyeicosatrienoic acids (5, 6-, 8, 9-, 11, $12-$, and 14, 15-EET) and by CYP $\omega$-hydroxylases to 20-hydroxyeicosatetraenoic acid (20-HETE) [19]. It is potent vasoconstrictor and induces oxidative stress. In clinical 
studies, it is associated with increased BMI and the metabolic syndrome [20]. COX pathway offer cardioprotection due to production of PGI2 by inducible COX 2 and blockade of this pathway may ultimately result into unopposed production of 20-HETE [19]. This could be the reason for increased BMI and impaired lipid profile in selective COX2-Is treated arthritic patients.

Surprisingly our study revealed significant difference in BSL in selective COX 2-Is group compared to controls but, this couldn't be justified as its LOX pathway that has predominant role in insulin release and COX inhibition doesn't affect this release [21]. COX1 and COX2 exert opposite effects on systemic blood pressure and renal function. COX2 inhibitors reduce renal medullary blood flow, decrease urine flow, and enhance the pressor effect of Angiotensin II. In contrast, the pressor effect of Angiotensin II is blunted by COX1 inhibition [22]. Nonselective NSAIDs are said to increase blood pressure by nonselective blocking of COX1and 2 while selective NSAIDs by blocking of COX 2; hence nonselective NSAIDs are considered more renal toxic. But in our study no significant increase was observed in both the groups.

In this study we have also explored the CV risk in subset arthritic patients i.e. with history of smoking, alcohol consumption and familial CVD which otherwise remained unexplored in majority of the earlier studies. History of familial CVD has positive correlation with CV risk as stated in earlier few studies[3, 4, 6]; our study results reflected higher CV risk in selective COX2-Is group (9.6\%). This high CV risk could be due to maximum number of arthritics (15 out of 28 ) with familial CVD were there in COX2-Is group, which confirms this positive correlation.

Smoking is one of the most important CV risk factors for the development and progression of atherosclerosis. COX-derived prostanoids mediate the pathogenic effects of cigarette smoking on vascular health. Higher CV risk in smokers $(23 \%)$ observed in arthritics treated with COX2-Is group could be explained on the basis of that all of these agents invariably cause an imbalance between PGI2 and TXA2; as they block COX2derived prostacyclin (PGI2) keeping TXA2 biosynthesis unopposed by COX 1 in smokers [23]. Several epidemiological investigations have shown that a low to moderate level (i.e.20g-70/day) of alcohol intake has definitive protective role against $\mathrm{CHD}$ and stroke. Mechanisms for cardioprotective effects include increased HDL, decreased LDL, prevention of clot formation, reduction in platelet aggregation, and lowering of plasma apolipoprotein (a). In contrast to this heavy intake (i.e. $<89 \mathrm{~g}-70 /$ day) increase the CV risk due to increased homocysteine levels [24]. In this study CV risk was found to be high (20\%) in COX2-Is group and alcohol consumption appears to compliment this.

\section{Conclusion}

CV risk of Selective COX 2-Is like rofecoxib, valdecoxib, lumiracoxib and celecoxib has been stated in earlier studies. Our study portrays the potential CV risk of etoricoxib; CV safety data of which is scare. With the results of this study, CV risk of COX 2-Is could be expressed as a class effect. Though COX 2-Is preferred over nonselective COX-Is due to 
cardiovascular, gastrointestinal \& renal toxicity of these agents and are said to be safe, the use of selective COX 2-Is must be restricted to the arthritic patients with absolute contraindications (i.e. peptic ulcer, asthma and renal disease) for nonselective NSAIDs. Thus this study could be a fruitful addition in CV safety data of selective COX2-Is.

\section{Acknowledgement}

The authors are thankful to Dr. A.V. Bhore, Dean SKNMC and Dr. Madhav Khadilkar, HOD Orthopedics, Dr Devendra Vartak, Associate Professor of Orthopedics, Dr. Dnyaneshwari Ghadage CCL I/C for providing facilities to carry out of the experiments of this work.

\section{References}

1. C. F. Kuo, S. F. Luo, L. C. See, I. J. Chou, H. C. Chang, and K. H. Yu, Rheumatol Int. 33 (2), 355 (2013). http://dx.doi.org/10.1007/s00296-012-2411-7

2. G. A. FitzGerald and C. Patrono, N. Engl. J. Med. 345, 433 (2001). http://dx.doi.org/10.1056/NEJM200108093450607

3. US Food and Drug Administration. FDA announces series of changes to the class of marketed non-steroidal anti-inflammatory drugs (NSAIDs). FDA News.

4. C. Bombardier, L. Laine, A. Reicin, D. Shapiro, R. Burgos-Vargas, B. Davis, R. Day, M.B. Ferraz, C. J. Hawkey, M. C. Hochberg, T. K. Kvien, and T. J. Schnitzer; VIGOR Study Group. N. Engl. J. Med. 343, 1520 (2000). http://dx.doi.org/10.1056/NEJM200011233432103

5. B. Levin Celecoxib in adenoma prevention: The PreSAP trial (FDA Advisory Committee on COX-2 Inhibitors and NSAIDS).

6. TMT Review: Cardiovascular safety of Celebrex. Available at: www.fda.gov/ohrms/dockets/dockets/04n0559/04N-0559 emc-000002-01.pdf. Accessed January 26, 2014.

7. M. E. Farkouh, H. Kirshner, R. A. Harrington, S. Ruland, F. W. Verheugt, T. J. Schnitzer, G. R. Burmester, E. Mysler, M. C. Hochberg, M. Doherty, E. Ehrsam, X. Gitton, G. Krammer, B. Mellein, A. Gimona, P. Matchaba, C. J . Hawkey, and J. H. Chesebro; TARGET Study Group. Lancet 364, 675 (2004). http://dx.doi.org/10.1016/S0140-6736(04)16894-3

8. P. M. Kearney, C. Baigent, J. Godwin, H. Halls, J. R. Emberson, and C. Patrono, BMJ. 332, 1302 (2006). http://dx.doi.org/10.1136/bmj.332.7553.1302

9. M. R. Abdel-Fadeil, Y. T. Kishk, O. G. Ahmed, and D. Gamal, Ibnosina J. Med. BS, 3 (4), 101 (2011).

10. D. H. Kim, N. Puri, K. Sodhi, J. R. Falck, N. G. Abraham, J. Shapiro, and M. L. Schwartzman, J. Lipid Res. 54, 786 (2013). http://dx.doi.org/10.1194/jlr.M033894

11. G. J. Hankey and J. W. Eikelboom, Stroke 34, 2736 (2003). http://dx.doi.org/10.1161/01.STR.0000097301.50041.6E

12. D. W. J.Clark, D. Layton, and S. A. W. Shakir, Drug Safe 27, 427 (2004). http://dx.doi.org/10.2165/00002018-200427070-00002

13. N. M. Davies and F. Jamali. J. Pharm. Pharmaceut. Sci. 7, 332 (2004).

14. I. S. Mackenzie, L. Wei, and T. M. MacDonald, Europ. J. Clin. Pharmacol. 69 (2), 133 (2013). http://dx.doi.org/10.1007/s00228-012-1335-1

15. M. Giorgi, T. W. Kim, A. Saba, M. R. Rouini, H. Yun, R. Ryschanova, and H. Owen, J. Pharmaceut. Biomed. Anal. 83, 28 (2013). http://dx.doi.org/10.1016/j.jpba.2013.04.024 
16. F. E. Silverstein, G. Faich, and J. L. Goldstein, L.S.Simon, T. Pincus, A. Whelton, R. Makuch, G. Eisen, N. M. Agrawal, W. F Stenson, A. M. Burr, W. W. Zhao, J. D. Kent, J. B. Lefkowith, K. M. Verburg, and G. S. Geis. JAMA, 284, 1247 (2000).

http://dx.doi.org/10.1001/jama.284.10.1247

17. B. Combe, G. Swergold, J. McLay, T. McCarthy, C. Zerbini, P. Emery, L. Connors, A. Kaur, S. Curtis, L. Laine, and C. P. Cannon, Rheumatology (Oxford), 48 (4), 425 (2009). http://dx.doi.org/10.1093/rheumatology/kep005

18. C. P. Cannon, S. P. Curtis, G. A. FitzGerald, H. Krum, A. Kaur, J. A. Bolognese, A. S. Reicin, C. Bombardier, M. E. Weinblatt, D. van der Heijde, E. Erdmann, and L. Laine; MEDAL Steering Committee. Lancet 18; 368 (9549), 1771-81(2006).

19. S. Trelle, S. Reichenbach, S. Wandel, et al. BMJ. 342, c7086 (2011). http://dx.doi.org/10.1136/bmj.c7086

20. G. J. Gross, J. R. Falck, E. R. Gross, M. Isbell, J. Moore, and K. Nithipatikom, Cardiovascular Res. 68, 18 (2005). http://dx.doi.org/10.1016/j.cardiores.2005.06.007

21. M. F. Ealsh and S. B. Pek, Life Sci. 34 (18), 1699 (1984). http://dx.doi.org/10.1016/0024-3205(84)90567-8

22. Z. Qi, C. M. Hao, R. I. Langenbach, R. M. Breyer, R. Redha, J. D. Morrow, and M. D. Breyer, J. Clin. Invest. 110 (1), 61 (2002). http://dx.doi.org/10.1172/JCI0214752

23. M. Hermann, H. Krum, and F. Ruschitzka, Circulation 112, 941 (2005). http://dx.doi.org/10.1161/CIRCULATIONAHA.105.567842

24. D. P. Agarwal, Alcohol and Alcoholism 37 (5), 409 (2002). http://dx.doi.org/10.1093/alcalc/37.5.409 